\title{
Graft-versus-host disease
}

\section{Severe hypercholesterolemia mediated by lipoprotein $X$ in patients with chronic graft-versus-host disease of the liver}

\author{
A Turchin ${ }^{1}$, DA Wiebe ${ }^{2}$, EW Seely ${ }^{1}$, T Graham $^{3}$, W Longo ${ }^{4}$ and R Soiffer ${ }^{5}$ \\ ${ }^{1}$ Division of Endocrinology, Diabetes and Hypertension, Brigham and Women's Hospital, Boston, MA, USA; ${ }^{2}$ Department of \\ Pathology and Laboratory Medicine, University of Wisconsin, Madison, WI, USA; ${ }^{3}$ Division of Endocrinology, Beth Israel Deaconess \\ Medical Center, Boston, MA, USA; ${ }^{4}$ Division of Hematology, University of Wisconsin, Madison, WI, USA; and ${ }^{5}$ Department of \\ Medical Oncology, Dana Farber Cancer Institute, Boston, MA, USA
}

\section{Summary:}

We describe a series of cases of extreme hypercholesterolemia mediated by lipoprotein $X$ in patients with chronic graft-versus-host disease of the liver after an allogeneic bone marrow transplant. All of the patients presented with a total cholesterol in excess of $1000 \mathrm{mg} / \mathrm{dl}(25.9 \mathrm{mmol} / \mathrm{l})$. At the time they were also noted to have pseudohyponatremia. Cholesterol appeared to be predominantly carried by lipoprotein $\mathrm{X}$. Intrahepatic cholestasis leading to reflux of bile lipoproteins into the bloodstream and subsequent formation of protein $X$ appears to be the mechanism underlying this phenomenon. Complications, including retinal cholesterol thromboembolism and cholesteroloma of the lung have been seen in the patient with the highest cholesterol levels. Severe hypercholesterolemia is an important, and likely more common than previously reported, long-term complication of allogeneic hematopoietic stem cell transplantation. It is important for clinicians to familiarize themselves with the diagnostic and therapeutic challenges this condition presents.

Bone Marrow Transplantation (2005) 35, 85-89.

doi:10.1038/sj.bmt.1704739

Published online 8 November 2004

Keywords: hyperlipidemia; hypercholesterolemia; graftversus-host disease; lipoprotein $\mathrm{X}$

While hypercholesterolemia remains a prevalent disorder in the Western world, few conditions have been documented to cause hypercholesterolemia above $1000 \mathrm{mg} / \mathrm{dl}$ (25.9 mmol/1). Differential diagnosis of hypercholesterolemia of this magnitude includes homozygous familial hypercholesterolemia, ${ }^{1}$ hepatic lipase deficiency, ${ }^{2}$ and obstructive biliary cholestasis. ${ }^{3,4}$ Such extreme hypercholesterolemia can lead to a number of serious, even fatal

Correspondence: Dr A Turchin, Division of Endocrinology, Diabetes and Hypertension, Brigham and Women's Hospital, 221 Longwood Avenue, Boston, MA 02115, USA; E-mail: aturchin@partners.org

Received 18 May 2004; accepted 27 August 2004

Published online 8 November 2004 sequelae, ranging from premature coronary artery disease (myocardial infarctions have been documented as early as 18 months of age in patients with homozygous familial hypercholesterolemia ${ }^{5}$ ) to hyperviscosity syndrome. ${ }^{6}$ Its treatment can be very difficult and require multiple medications $^{7,8}$ as well as more invasive measures, such as lowdensity lipoprotein (LDL) apheresis ${ }^{9}$ or plasmapheresis. ${ }^{6}$

Allogeneic hematopoietic stem cell transplantation, an increasingly common treatment for a number of malignant and nonmalignant disorders, often leads to graft-versus-host disease (GVHD) of the liver (40\% of recipients from HLAmatched related donors $\left.{ }^{10}\right)$. GVHD of the liver frequently presents with a cholestatic picture. However, to our knowledge only two cases of severe hypercholesterolemia in bone marrow transplant patients have been reported in the literature. ${ }^{11,12}$ Consequently, there may be insufficient awareness of this important complication among the physicians caring for these frequently very ill patients. From our experience, it appears that it may be more frequent than commonly perceived. In this paper, we describe three cases of extreme hypercholesterolemia developing in patients with chronic GVHD of the liver, and analyze its presentation, possible sequelae, and management.

\section{Methods}

\section{Study population}

Three patients with severe hypercholesterolemia mediated by lipoprotein $\mathrm{X}$ after allogeneic hematopoietic stem cell transplantation, who were seen by us over a 2-month period, are described.

The Institutional Review Boards (IRBs) from the respective hospitals did not require a review of this study. All patients were transplanted on treatment plans approved by the IRB or an equivalent peer-review committee.

\section{Biochemical analysis}

Serum was subjected to sequential ultracentrifugation to separate it into three fractions: density $<1.006 \mathrm{~g} / \mathrm{ml}$ (very low density), $1.006-1.063 \mathrm{~g} / \mathrm{ml}$ (low density), and $>1.063 \mathrm{~g} / \mathrm{ml}$ (high density). The resulting fractions were subjected, together with controls, to $1 \%$ agarose gel electrophoresis using barbital 
86

buffer (pH 8.6) in a standard Corning electrophoresis system for $30 \mathrm{~min}$ and stained for protein (Amido Black) and lipids (Fat Red 7B). Concentrations of cholesterol, gammaglutamyltransferase, and alkaline phosphatase were measured in the high- and low-density fractions.

\section{Case I}

A 64-year-old woman with history of acute myelogenous leukemia (AML), who underwent allogeneic hematopoietic stem cell transplantation 2 years earlier, presented to the hospital with progressive liver dysfunction due to GVHD (confirmed by liver biopsy). Some details of this patient's course have been previously reported. ${ }^{13}$ On admission, the patient's total bilirubin was $9.0 \mathrm{mg} / \mathrm{dl}(153.9 \mu \mathrm{mol} / \mathrm{l})$, alkaline phosphatase $449 \mathrm{U} / 1$, AST $101 \mathrm{U} / 1$, and ALT $142 \mathrm{U} / 1$. Her sodium was found to be decreased at $124 \mathrm{mmol} / \mathrm{l}$ (as measured by indirect potentiometry). Further investigation showed this to be due to pseudohyponatremia (direct potentiometry measurements showed the sodium level to be $135 \mathrm{mmol} / 1)$; the patient's lipid profile was measured and her total cholesterol was found to be $1836 \mathrm{mg} / \mathrm{dl}$ (47.6 mmol/1), HDL cholesterol $68 \mathrm{mg} / \mathrm{dl}(1.76 \mathrm{mmol} / \mathrm{l})$, and triglycerides $208 \mathrm{mg} / \mathrm{dl}(2.35 \mathrm{mmol} / \mathrm{l})$; LDL cholesterol was not directly measured. Her only known previous measurement of lipid profile was done 2 years prior to admission and showed total cholesterol of $181 \mathrm{mg} / \mathrm{dl}$ (4.69 mmol/l), HDL cholesterol $51 \mathrm{mg} / \mathrm{dl}(1.32 \mathrm{mmol} / \mathrm{l})$, and triglycerides $136 \mathrm{mg} / \mathrm{dl}(1.54 \mathrm{mmol} / \mathrm{l})$. Dermatological examination did not show any xanthomata. Serum viscosity was slightly elevated at 1.9 centipoise; she had no signs or symptoms consistent with hyperviscosity syndrome. Her medications included high-dose $(50 \mathrm{mg} /$ day) prednisone, mycophenolate, and tacrolimus. Screening for other potential causes of hypercholesterolemia revealed elevated TSH $(72 \mu \mathrm{U} / \mathrm{ml})$ and low total T4 $(0.6 \mu \mathrm{g} /$ $\mathrm{dl} ; 7.72 \mathrm{nmol} / \mathrm{l})$ and $\mathrm{T} 3(41 \mathrm{ng} / \mathrm{dl} ; 0.63 \mathrm{nmol} / \mathrm{l})$.

The patient's serum was sequentially ultracentrifuged to separate it into very low-density $(<1.006 \mathrm{~g} / \mathrm{ml})$, low-density $(1.006-1.063 \mathrm{~g} / \mathrm{ml})$, and high-density $(>1.063 \mathrm{~g} / \mathrm{ml})$ fractions as described above. Gel electrophoresis of the fractionated serum showed a broad lipoprotein band in the patient's low-density fraction. Cholesterol as well as liver enzymes were measured in each of these fractions, demonstrating high levels of alkaline phosphatase and gamma-glutamyltransferase associated with the lipoprotein in the low-density fraction. These findings, in conjunction with relatively low triglyceride levels, were consistent with the presence of large amounts of lipoprotein X. ${ }^{14-18}$

The patient was started on colestipol, gradually escalating the dose to a maximum of $30 \mathrm{~g} /$ day. A month later, her total cholesterol had decreased to $1114 \mathrm{mg} / \mathrm{dl}(28.9 \mathrm{mmol} / \mathrm{l})$. However, her liver dysfunction had progressed over the same time. The patient expired from infectious complications related to immunosuppression shortly afterwards.

\section{Case II}

The patient was a 47-year-old woman with a history of chronic myelogenous leukemia (CML) who had undergone allogeneic bone marrow transplantation 10 months previously. Her course had been complicated by chronic GVHD of the liver (diagnosed by liver biopsy), chronic renal insufficiency, and glucocorticoid-induced diabetes mellitus. She was found to have total cholesterol of $1236 \mathrm{mg} / \mathrm{dl}(32.0 \mathrm{mmol} / \mathrm{l}) 10 \mathrm{months}$ after the transplant. At 3 months after the transplant, her total cholesterol had been measured to be $407 \mathrm{mg} / \mathrm{dl}(10.5 \mathrm{mmol} / \mathrm{l})$; it then rose to $954 \mathrm{mg} / \mathrm{dl}(24.7 \mathrm{mmol} / \mathrm{l}) 9$ months after the transplant. Her medications over this period of time included prednisone, mycophenolate, and tacrolimus. Thyroid function tests showed $\mathrm{TSH}$ to be $0.16 \mu \mathrm{U} / \mathrm{ml}$ and free thyroxine $0.8 \mathrm{ng} / \mathrm{dl}$ (10.3 pmol/1). Most of the cholesterol was demonstrated to be carried by lipoprotein-X using an ultracentrifugation and gel electrophoresis-based method identical to the technique employed for Patient 1. Her dyslipidemia was not treated due to the concomitant progressive hepatic dysfunction. She died from complications of liver failure secondary to chronic GVHD 1 year after the transplant.

\section{Case III}

The patient was a 37-year-old man with a history of CML who underwent allogeneic bone marrow transplantation in February of 2002. After 9 months, he developed chronic GVHD of the liver (confirmed by biopsy). Over the next 2 weeks his sodium (as measured by indirect potentiometry) declined from 140 to $129 \mathrm{mmol} / 1$. This was shown to be due to pseudohyponatremia (sodium measured by direct potentiometry was determined to be $135 \mathrm{mmol} / \mathrm{l}$ ). His total cholesterol was subsequently measured to be $977 \mathrm{mg} / \mathrm{dl}$ (25.3 mmol/1), HDL cholesterol $23 \mathrm{mg} / \mathrm{dl}(0.60 \mathrm{mmol} / \mathrm{l})$, triglycerides $240 \mathrm{mg} / \mathrm{dl}(2.71 \mathrm{mmol} / \mathrm{l})$, measured LDL cholesterol $218 \mathrm{mg} / \mathrm{dl}(5.65 \mathrm{mmol} / \mathrm{l})$. The total cholesterol 6 months prior to the transplant was $221 \mathrm{mg} / \mathrm{dl}(5.72 \mathrm{mmol} / \mathrm{l})$. Most of the cholesterol was demonstrated to be carried by lipoprotein-X using an ultracentrifugation and gel electrophoresis-based method, identical to that described above. His medications included sirolimus, mycophenolate, and prednisone. Thyroid function tests showed the TSH to be $0.56 \mu \mathrm{U} / \mathrm{ml}$ and free thyroxine $0.8 \mathrm{ng} / \mathrm{dl}(10.3 \mathrm{pmol} / 1)$. No antihyperlipidemic treatment was initiated due to the liver disease. His GVHD was successfully treated with immunosuppression and, as his liver function improved, his cholesterol had decreased to $329 \mathrm{mg} / \mathrm{dl}(8.52 \mathrm{mmol} / \mathrm{l}) 10$ months later without specific intervention.

\section{Discussion}

Severe hypercholesterolemia is not a commonly reported complication of allogeneic hematopoietic stem cell transplantation. Several possible etiologies could be identified for the patients we described.

A number of medications used in immunosuppressive regimens have been documented to cause dyslipidemias. These include cyclosporine, ${ }^{19}$ tacrolimus, ${ }^{20}$ sirolimus, ${ }^{21,22}$ mycophenolate, ${ }^{23}$ and glucocorticoids. ${ }^{24}$ Cholesterol levels between 200 and $300 \mathrm{mg} / \mathrm{dl}(5.18-7.77 \mathrm{mmol} / \mathrm{l})$, mediated by increased LDL cholesterol levels, and triglyceride levels 
between 200 and $350 \mathrm{mg} / \mathrm{dl}(2.26-3.96 \mathrm{mmol} / \mathrm{l})$ are usually described. All of the patients in this series were taking one or more of these medications. While their contribution to the patients' hypercholesterolemia cannot be ruled out, it must be noted that most of the cholesterol in these patients was not carried by LDL as is characteristic of the medication-induced dyslipidemia, but by lipoprotein $\mathrm{X}$; it is therefore unlikely that the drugs played more than a secondary role in the patients' conditions. However, medication-mediated hypercholesterolemia remains an important complication of allogeneic bone marrow transplantation, which should be monitored.

Hypothyroidism, which was pronounced in the first patient but absent in all others, is a known complication of allogeneic hematopoietic stem cell transplantation. ${ }^{25}$ It is also well documented to cause hyperlipidemia. ${ }^{26}$ However, the typical range of cholesterol levels seen in hypothyroidism is well below the levels observed in this patient. On average, total cholesterol levels in patients with both primary and secondary hypothyroidism are between 200 and $300 \mathrm{mg} / \mathrm{dl}(5.18-7.77 \mathrm{mmol} / \mathrm{l})$, with occasional outliers reaching $600 \mathrm{mg} / \mathrm{dl}(15.6 \mathrm{mmol} / 1) .{ }^{27}$ Importantly, unlike in this patient, most of the excess cholesterol in hypothyroidism-induced hypercholesterolemia is carried by LDL. Consequently, it is also unlikely to have played a dominant role in these patients' condition.

Agarose gel electrophoresis demonstrated that hypercholesterolemia in all of the patients described in this series was mediated mostly by lipoprotein $\mathrm{X}$ rather than LDL. Lipoprotein $\mathrm{X}$ is present in patients with intra- or extrahepatic cholestasis, lecithin:cholesterol acyltransferase (LCAT) deficiency, and in newborn infants with immature liver function. ${ }^{18,28}$ It is composed primarily of phospholipids and unesterified cholesterol. Reflux of bile into the bloodstream has been hypothesized to be a possible mechanism for its formation. Given that LCAT deficiency and other congenital disorders of lipid metabolism had been excluded by previously documented lower lipid levels in all of these patients, their hyperlipidemia was apparently due to intrahepatic cholestasis caused by chronic GVHD of the liver. Chronic GVHD of the liver is an immunemediated disorder which can appear anywhere from 2 months to 2 years after transplantation and typically presents with a cholestatic picture. ${ }^{29}$ Other cholestatic liver diseases, such as primary biliary cirrhosis, have long been known to occasionally result in severe hypercholesterolemia; ${ }^{4}$ however, this degree of hypercholesterolemia is not known to be common in chronic GVHD of the liver.

The data on the three patients presented in this paper as well as two other patients with this condition previously reported in the literature are summarized in Table $1 .^{11,12} \mathrm{~A}$ characteristic presentation involves development of chronic GVHD of the liver within 1 year after allogeneic bone marrow transplantation followed by new onset pseudohyponatremia which typically prompts the measurement of the cholesterol level. While a number of sources have stated in the recent years that pseudohyponatremia is nearly extinct due to the changes in laboratory equipment, ${ }^{30-32}$ this in fact is no longer the case, and most modern instruments are susceptible to this error. ${ }^{13}$ Apart from the pseudohyponatremia, most patients did not suffer any

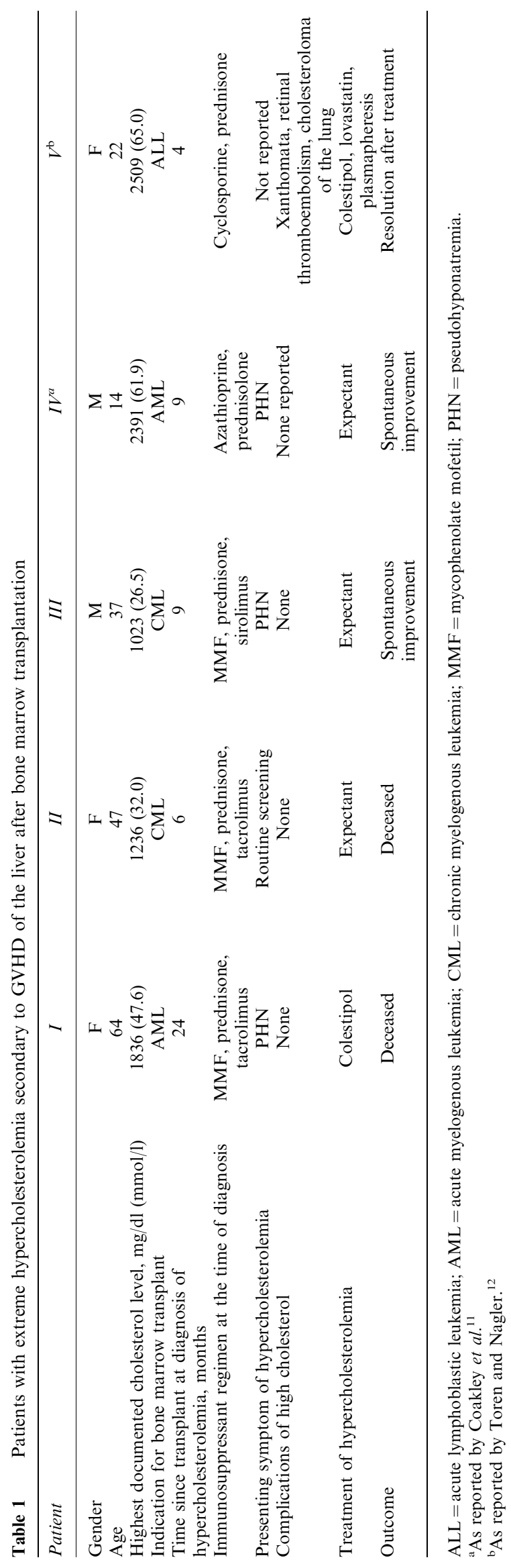


complications of their hypercholesterolemia; however, the one with the highest cholesterol level $(2509 \mathrm{mg} / \mathrm{dl}$; $65.0 \mathrm{mmol} / \mathrm{l})$ developed xanthomata, retinal cholesterol thromboembolism, and a cholesteroloma of the lung, all of which resolved after treatment. ${ }^{12}$ In addition to this, hyperviscosity syndrome has been reported in at least one patient with severe hypercholesterolemia mediated by lipoprotein $\mathrm{X}$ due to primary biliary cirrhosis. ${ }^{6}$ None of the patients reported have been observed for a sufficient period of time to allow conclusions about the risk of development of vascular disease.

Given the potential complications of lipoprotein Xmediated hypercholesterolemia, it is important to consider available therapeutic options. Treatment of the underlying GVHD of the liver by adjustment of immunosuppressant regimens remains the mainstay of therapy. This strategy led to resolution or significant improvement of hypercholesterolemia in three out of the five patients. However, GVHD is not always amenable to the currently available treatment, and other approaches may need to be considered to prevent sequelae of extreme hypercholesterolemia. The choice is limited as most of the antihyperlipidemic medications cannot be safely used in patients with significant hepatic damage. In cases with severe complications, plasmapheresis can be employed, as has been reported for one of the patients with GVHD-induced lipoprotein X hypercholesterolemia. ${ }^{12}$ As illustrated in this review, extreme hypercholesterolemia, confounded by other comorbidities in these complicated patients, is probably more common than previously reported; it is therefore important that health care providers for this group of patients are aware of the problem, its potential sequelae, and management.

\section{References}

1 Sprecher DL, Schaefer EJ, Kent KM et al. Cardiovascular features of homozygous familial hypercholesterolemia: analysis of 16 patients. Am J Cardiol 1984; 54: 20-30.

2 Connelly PW, Hegele RA. Hepatic lipase deficiency. Crit Rev Clin Lab Sci 1998; 35: 547-572.

3 McIntyre N, Harry DS, Pearson AJG. The hypercholesterolaemia of obstructive jaundice. Gut 1975; 16: 379-391.

4 Dickson ER, Fleming CR, Ludwig J. Primary biliary cirrhosis. In: Popper H, Schaffner F (eds). Progress in Liver Diseases, Vol. 6 Grune \& Stratton: New York, 1979, pp 487-528.

5 Coetzee GA, van der Westhuyzen DR, Berger GM et al. Low density lipoprotein metabolism in cultured fibroblasts from a new group of patients presenting clinically with homozygous familial hypercholesterolemia. Arteriosclerosis 1982; 2: 303-311.

6 Rosenson RS, Baker AL, Chow MJ et al. Hyperviscosity syndrome in a hypercholesterolemic patient with primary biliary cirrhosis. Gastroenterology 1990; 98: 1351-1357.

7 Illingworth DR. How effective is drug therapy in heterozygous familial hypercholesterolemia? Am J Cardiol 1993; 72: 54D$58 \mathrm{D}$.

8 Malloy MJ, Kane JP, Kunitake ST et al. Complementarity of colestipol, niacin, lovastatin in treatment of severe familial hypercholesterolemia. Ann Intern Med 1987; 107: 616-623.

9 Gordon BR, Kelsey SF, Bilheimer DW et al. Treatment of refractory familial hypercholesterolemia by low-density lipoprotein apheresis using an automated dextran sulfate cellulose adsorption system. The Liposorber Study Group. Am $J$ Cardiol 1992; 70: 1010-1016.

10 Przepiorka D, Anderlini P, Saliba R et al. Chronic graftversus-host disease after allogeneic blood stem cell transplantation. Blood 2001; 98: 1695-1700.

11 Coakley JC, Vervaart PP, McKay MRG. Factitious hyponatremia in a patient with cholestatic jaundice following bone marrow transplantation. Pathology 1986; 18: 158-159.

12 Toren A, Nagler A. Solitary pulmonary cholesteroloma, multiple xanthelasmas, lipemia retinalis complicating hypercholesterolemia after bone marrow transplantation. Bone Marrow Transplant 1996; 18: 457-459.

13 Turchin A, Seifter JL, Seely EW. Mind the gap. $N$ Engl J Med 2003; 349: 1463-1466.

14 Huseby NE. Multiple forms of serum gamma-glutamyltransferase. Association of the enzyme with lipoproteins. Clin Chim Acta 1982; 124: 103-112.

15 Miller J. Dyslipoproteinaemia of liver disease. Bail Clin Endocrinol Metab 1990; 4: 807-831.

16 Van Hoof VO, Lepoutre LG, Hoylaerts MF et al. Improved agarose electrophoretic method for separating alkaline phosphatase isoenzymes in serum. Clin Chem 1988; 34: 1857-1862.

17 Wolf P. Clinical significance of serum high-molecular-mass alkaline phosphatase, alkaline phosphatase-lipoprotein-X complex, intestinal variant alkaline phosphatase. J Clin Lab Anal 1994; 8: 172-176.

18 Seidel D, Alaupovic P, Furman RH. A lipoprotein characterizing obstructive jaundice. Method for quantitative separation, identification of lipoproteins in jaundiced subjects. $J$ Clin Invest 1969; 48: 1211-1223.

19 Kuster GM, Drexel H, Bleisch JA et al. Relation of cyclosporine blood levels to adverse effects on lipoproteins. Transplantation 1994; 57: 1479-1483.

20 Satterthwaite R, Aswad S, Sunga V et al. Incidence of new-onset hypercholesterolemia in renal transplant patients treated with FK506 or cyclosporine. Transplantation 1998; 65: 446-449.

21 Chueh SC, Kahan BD. Dyslipidemia in renal transplant recipients treated with a sirolimus, cyclosporine-based immunosuppressive regimen: incidence, risk factors, progression, prognosis. Transplantation 2003; 76: 375-382.

22 Morrisett JD, Abdel-Fattah G, Hoogeveen R et al. Effects of sirolimus on plasma lipids, lipoprotein levels, fatty acid metabolism in renal transplant patients. J Lipid Res 2002; 43: $1170-1180$.

23 Roche Laboratories. Cellcept ${ }^{\circledR}$ (mycophenolate mofetil) Complete Product Information (online), 2004 (cited October 14, 2004). Available from: URL: http//www.rocheusa.com/ products/cellcept/pi.pdf.

24 Sholter DE, Armstrong PW. Adverse effects of corticosteroids on the cardiovascular system. Can J Cardiol 2000; 16: 505-511.

25 Al-Fiar FZ, Colwill R, Lipton JH et al. Abnormal thyroid stimulating hormone (TSH) levels in adults following allogeneic bone marrow transplants. Bone Marrow Transplant 1997; 19: 1019-1022.

26 Kutty KM, Bryant DG, Farid NR. Serum lipids in hypothyroidism - a re-evaluation. J Clin Endocrinol, Metab 1978; 46: $55-56$.

27 O'Brien T, Dinneen SF, O'Brien PC et al. Hyperlipidemia in patients with primary, secondary hypothyroidism. Mayo Clin Proc 1993; 68: 860-866.

28 Glomset JA, Nichols AV, Norum KR et al. Plasma lipoproteins in familial lecithin-cholesterol acyltransferase deficiency. J Clin Invest 1973; 52: 1078-1092.

29 Strasser SI, Shulman HM, McDonald GB. Cholestasis after hematopoietic cell transplantation. Clin Liver Dis 1999; 3: $651-668$. 
30 Lewis III JL. Water, electrolyte, mineral and acid-base metabolism. In: Beers MH, Berkow R (eds). The Merck Manual of Diagnosis and Therapy. Merck Research Laboratories: Whitehouse Station, NJ, 1999, pp 120-164.

31 Robinson AG, Verbalis JG. Posterior pituitary gland. In: Larsen PR, Kronenberg HM, Melmed S, Polonsky KS (eds).
Williams Textbook of Endocrinology. W.B. Saunders Company: St Louis, 2002, pp 281-329.

32 Fukagawa M, Kurokawa K, Papadakis MA. Fluid and electrolyte disorders. In: Tierney Jr LM, McPhee SJ, Papadakis MA (eds). Current Medical Diagnosis and Treatment. The McGraw-Hill Companies, Inc.: New York, 2003, pp 839-866. 